\title{
Practical Mechanism Design and Strategic Choice of China's Industry Green Transformation: Base on the Perspective of Game Theory
}

\author{
Chaofan Chen $^{1} \&$ Yun Wang ${ }^{1}$ \\ ${ }^{1}$ School of Economics and Resource Management, Beijing Normal University, Beijing, China \\ Correspondence: Chaofan Chen, School of Economics and Resource Management, Beijing Normal University, \\ HaiDian District, Beijing, China. Tel: 1-517-505-6374. E-mail: ccffwyy@163.com
}

Received: Auguest 20, 2015

Accepted: October 22, 2015

Online Published: October 25, 2015

doi:10.5539/ijef.v7n11p178

URL: http://dx.doi.org/10.5539/ijef.v7n11p178

\begin{abstract}
Nowadays, green economy has become the trend of world, and an industrial revolution as the core of green development has emerged. China's industry experiences 30 years development, the resources and environment problems highlight increasingly, so it needs to transform into green development. However, both academic and practice do not have perfect practical mechanism of green transformation, and is also lack of strategic support system. Given this, Firstly, the paper researches the interactive relationship among main bodies in china's industry green transformation by using the game theory; Secondly, on basis of the game results, focusing on different bodies' main responsibilities and interests, we design the practical industry green transformation mechanism which taking the government as leading body, the industry circle \& industrial enterprises \& public as executing body, and the financial institution \& transaction center \& scientific research institute etc. as supporting body; Finally, in order to establish the policy framework, we propose "six in one" strategic choice of industry green transformation from government, region, industry, enterprise, society and individual's view.
\end{abstract}

Keywords: China's industry, green transformation, game analysis, practical mechanism, strategic choice

\section{Introduction}

At present, china's industrial economy is in the middle-late stage of accelerating industrialization, facing the staged problems such as industrial investment expanding, energy demand increasing, and environmental pollution aggravating etc. For the governance of these industrial environment problems, many regions still go the old path of developed countries, adopting end-of-pipe treatment especially in designing institution and mechanism, and lacking initiative consciousness and behavior of green transformation. As the prominent industrial powers, we should draw lessons from developed countries of industry transformation practical mechanism and strategic choice in industrial pollution controlling, and gradually abandon the pattern of "pollution first, treatment later", constantly absorb the world's advanced industrial upgrading and environmental governance concept, give full play to the advantage of backwardness, so as to accelerate green development. Therefore, it needs to attach great importance to industry green transformation at the strategic level, strengthen the innovation of the institution and mechanism, and perfect the policy system of the industry green transformation. In this strategic framework, the government, industry, enterprise, society and the public are all important bodies, only constantly enrich the industrial green transformation policy in the strategic network, can mobilize the enthusiasm of each element to support the industrial green transformation.

Many scholars combine with characteristics of china's industry development and draw relevant experiences from developed countries, so as to put forward china's industry green transformation mechanism and strategy. It can provide a valuable reference for us to design strategy and policy system which conforms to "china's new-type industrialization". Overall, the studies of industry green transformation mechanism focus on the concept and the policy level (Bei Jin, 2011; Angang Hu, 2012). Yihu Wang and Wen Chen (2007) put forward the concept model of industry green transformation mechanism based on the depth analysis of varieties of internal and external driving forces of industrial green transformation. Their research suggested that in different stages of industrial development, driving mechanism of industrial green transformation was different, the macro environment, market and social pressures would form the internal driving mechanism, and promoted the industry green transformation. Guoshen Zheng (2009) discussed the development mechanism of green industry from multi-level and multi-dimensional perspective. He analyzed green industry running mechanism through five aspects: 
cooperation and information sharing mechanism, trust mechanism, coordination mechanism, risk management mechanism and evolution and innovation mechanism. Industrial economy research institute of Chinese academy of social sciences (2011) showed that the benefit of industrial green transformation was much higher than its cost, which would become the basic power of china's industrial green transformation. Therefore should establish environmental regulation, energy conservation and emissions reduction mechanism, green technology research and industrialization application mechanism, international cooperation and coordination mechanism, innovation mechanism, etc. Weimin Jing and Lu Zhang (2014) adopted the panel data of 33china's industries to investigate the influence of environmental regulation and opening up on industry green innovation mechanism. The study showed that, reasonable environmental regulation and a high level of opening up could promote the industry green innovation, thus have a positive impact on industry green transformation. Apart from focusing on industry green transformation practical mechanism, many scholars also care about china's industrial green transformation strategy design, such as: Hongming Liu (2009) argued that, in order to promote china's industry green transformation, the strategy should include the following aspects: relied on leading force of the government, further increased the intensity of environmental regulation; guided the whole society to establish green concepts; intensified information disclosure and publicity; established reasonable and effective environmental market mechanism; developed circular economy and realized the sustainable utilization of resources. Qingxin Lan and Jing Han (2012) thought that, based on china's industry development, china's industrial green transformation could adopt the following strategies: perfecting green policy system; promoting industrial technology upgrading; developing agglomeration economy; promoting industrial convergence. Yan Chen (2013) argued that, china's industrial green and low-carbon development strategy included: promoted industrial energy saving and consumption reducing; developed circular economy; encouraged related service industry development such as energy conservation and environmental protection and closed down backward production facilities quickly. Junan Li (2013) stated the china's industry green development strategy from innovation perspective. He thought that, the focus of the green industry development in china is driven by innovation which could reform and upgrade traditional industries, cultivate and develop high-tech and green industry. The key is strengthening institutional incentive, promoting scientific and technological innovation, training staff and deepening international cooperation.

Make a general survey of the above studies, it is easy to find that, no matter the scholars from which view to design the china's industry green transformation practical mechanism and strategic task, it is based on an idea: in the current situation of resources exhausted and environment pollution worsened, the traditional industrial development path is unsustainable, it is imperative to speed up the industrial green transformation and upgrading. But summarize the related literatures, we can find the shortcomings of the existing researches easily. Firstly, few scholars can design china's industrial green transformation mechanism based on the view of game theory, and if they can summarize the game relation among different main bodies that involve in the industry green transformation process, it will help us design the industry green transformation practical mechanism better; Secondly, most scholars just emphasize a certain aspect of strategic task to promoting china's industrial green transformation, while they have not built strategic network. Based on the shortcomings of the two points, this paper uses the game theory method, designs china's industry green transformation mechanism from leading body, executing body, and supporting body three aspects, which focuses on different bodies' responsibilities and interests. Finally, we will put forward the "six in one" policy framework and strategic choice.

\section{The Game Analysis of China's Industry Green Transformation}

In order to have a deeper understanding of china's industry green transformation and design china's industry green transformation practical mechanism, we will build a game model to analyze the relationship among the main bodies. In order to analyze conveniently, we classify the game bodies that involve in industrial green transformation into three types: government (central and local government), industry circle (industry and enterprise), society (social and the public).At the same time, thinking about the research points of the article, we consider two main games: government- industry circle and industry circle- society.

\subsection{Game Analysis between Government and Industry Circle}

As we know, government is the enabler of industry green transformation and industry circle is the core executing body of green transformation, the game between the two presents a long-term, dynamic characteristic. We will build a two-stage game model between the government and industry circle to explore the key factors of the government and industry circle's choice in the game strategy. The assumption of game model is as follows. (a) The game model is divided into short-term and long-term stage. In the short term, the initial economic benefits of government and industry circle is $R_{g}$ and $R_{e}$ respectively. The government in order to promotes industry green transformation, pays certain amount of subsidies $S$ to industry circle (for example, government's subsidies and 
incentives for industrial pollution controlling, etc.), while in the long term, with deepening practice of industry green transformation, government's subsidies disappear. At this point, if the industry circle no longer participates in industry green transformation because of government's subsidies cancelling, the government will bear part of the loss $C_{g}$, at the same time, the industry circle will suffer penalty $F$ from the government. In the short term, industry circle in order to cooperate with the government's industry green transformation, it also needs to pay a certain cost of $C_{e}$, while the government will weigh the interests, giving subsidies $S$ timely, and $S \leq C_{e}$. Because at this time society is not well understanding industry green transformation, it cannot make the transformation smoothly, the industry circle will bear part of the interests reducing $a R_{e}(0<\mathrm{a}<1)$. (b) If industry green transformation can obtain the significant results, the government thus gain good external benefits $X_{g}$; Industry circle makes effort to cooperate with the government reforms, promotes practice of industry green transformation, it will obtain good external benefits $X_{e}$. If both take a negative act, they will lose this part of the external benefit. (c) With the further development of industry green transformation, the industry circle begins to enjoy good economic returns, thus making profits $b R_{e}(b>1)$, if industry circle do not practice well in industry green transformation, it can only benefit $c R_{e}(0<c<a<1)$. (d) Revenue function of government and industry circle are all totaled by short-term and long-term. This model assumes that the information is fully, completely, and does not consider the effect of financial parameters. Based on the above assumptions, we can build the long term game matrix of the government and industry circle, see table1.

Table 1. Game matrix of the government and industry circle

\begin{tabular}{|c|c|c|c|}
\hline & & \multicolumn{2}{|c|}{ government } \\
\hline & & promotion & non promotion \\
\hline \multirow{2}{*}{ industry circle } & participation & $\begin{array}{c}\left(a R_{e}+S+X_{e}-C_{e}\right)+\left(b R_{e}+X_{e}\right) \\
\left(R_{g}+X_{g}-S\right)+\left(R_{g}+X_{g}\right)\end{array}$ & $\begin{array}{c}\left(a R_{e}+X_{e}-C_{e}\right)+\left(b R_{e}+X_{e}\right), \\
\left(R_{g}-X_{g}\right)+\left(R_{g}-X_{g}\right)\end{array}$ \\
\hline & non participation & $\begin{array}{c}R_{e}+\left(c R_{e}-F-X_{e}\right), \\
\left(R_{g}+X_{g-} C_{g}\right)+\left(R_{g}+F+X_{g}-C_{g}\right)\end{array}$ & $\begin{array}{c}R_{e}+\left(c R_{e^{-}} X_{e}\right), \\
\left(R_{g}-X_{g-} C_{g}\right)+\left(R_{g^{-}} X_{g-} C_{g}\right)\end{array}$ \\
\hline
\end{tabular}

We analyze the equilibrium conditions of the model. Set up $\chi_{i j}$ denotes the industry circle's revenue when industry circle selects $i$ strategy, government chooses $j$ strategy; $\kappa_{i j}$ denotes the government's revenue when industry circle selects $i$ strategy, government chooses $j$ strategy. The equilibrium analysis of the four strategies as follows.

Firstly, when the government choses to promote the practice of industry green transformation, the revenue of industry circle participates or not in the practice of industry green transformation as the formula 1 , calculate the revenue gap of industry circle as formula 2 .

$$
\begin{gathered}
\chi_{11}=\left(a R_{e}+S+X_{e}-C_{e}\right)+\left(b R_{e}+X_{e}\right), \quad \chi_{21}=R_{e}+\left(c R_{e}-F-X_{e}\right) \\
\Delta_{1}=\chi_{11}-\chi_{21}=(a+b-c-1) R_{e}+3 X_{e}+S+F-C_{e}
\end{gathered}
$$

If $\Delta_{1}>0$, we will have formula 3:

$$
(a+b-c-1) R_{e}+3 X_{e}+S+F>C_{e}
$$

Formula 3 indicates that, first of all, in the game of industry green transformation, government promotes the transformation, as a rational economic man, the key of industry circle whether or not involve is whether its revenue greater than its costs. Because $0<c<a<1<b$, we get $(a+b-c-1)>0$, that is the bigger revenue gap between participating or not of industry circle, the greater enthusiasm of the industry circle participating. Secondly, we see that the participating enthusiasm of industry circle is related to the opportunity cost of $S, F$, that is, when the government gives more subsidies to industry circle, the higher total revenue of industry circle participating in the transformation; when government gives industry circle more penalties, the industry circle will bear greater revenue loss. Therefore, when the government's subsidies $F$ or penalties $S$ are higher, the enthusiasm of industry circle participating in industry green transformation will be enhanced. Moreover, the social benefit of the industry circle is also one of power to participating in green transformation. If the industry circle carries out the policy of the government, it will obtain a good social reputation and social identity. If the 
society and residents' consciousness of energy conservation and emissions reduction is intense, the participating enthusiasm in industry green transformation will be high, and they will more favor in the enterprises who has done the green transformation, so as to make the enterprises' external income increase, then the revenue gap of participating industry green transformation or not will be further expanded, the motivation of industry circle will be enhanced.

Secondly, when the government does not chose to promote industry green transformation, the revenue of industry circle participates or not in the practice of industry green transformation as the formula 4 , and calculate the revenue gap of industry circle as formula 5.

$$
\begin{gathered}
\chi_{12}=\left(a R_{e}+X_{e}-C_{e}\right)+\left(b R_{e}+X_{e}\right), \quad \chi_{22}=R_{e}+\left(c R_{e}-X_{e}\right) \\
\Delta_{2}=\chi_{12}-\chi_{22}=(a+b-c-1) R_{e}+3 X_{e}-C_{e}
\end{gathered}
$$

Formula 5 shows that when the government does not chose to promote industry green transformation, the key selection factor for the industry circle are the difference of economic revenue $(a+b-c-1)$, social benefits Xe, and participating cost $C e$. At this point, the larger gap of economic revenue of industry circle obtaining, the higher external social benefits, the lower economic cost, the stronger participation motive of the industry circle will have, otherwise, it will be weaker.

Thirdly, when the industry circle choses to participate in industry green transformation, the revenue of government promotes or not the practice of industry green transformation as the formula 6 , calculate the revenue gap of government as formula 7.

$$
\begin{gathered}
\kappa_{11}=\left(R_{g}+X_{g}-S\right)+\left(R_{g}+X_{g}\right), \quad \kappa_{12}=\left(R_{g}-X_{g}\right)+\left(R_{g}-X_{g}\right) \\
\Delta_{3}=\kappa_{11}-\kappa_{12}=4 X_{g}-S
\end{gathered}
$$

Formula 7 shows that when the industry circle is committed to participate in the industrial green transformation, the key of the government promoting transformation lies in two aspects: the most important is the social benefits of the government, if the government force the industry green transformation, which is the implementation of energy-saving \& emission reduction policy and the long term planning of sustainable development. It can not only hold a high praise in the society, even can win the good reputation in the world. In this case, the intention of government to promote industry green transformation will be very strong. Of course, the cost of government promoting the transformation is also need to be considered, if the government subsidies and other economic incentives exceed the government's load, so the willingness of government to promoting transformation will be relatively weak.

Fourthly, when the industry circle does not chose to participate in industry green transformation, the revenue of government promotes or not the practice of industry green transformation as the formula 8, calculate the revenue gap of government as formula9.

$$
\begin{gathered}
\kappa_{21}=\left(R_{g}+X_{g}-C_{g}\right)+\left(R_{g}+F+X_{g}-C_{g}\right), \quad \kappa_{22}=\left(R_{g}-X_{g}-C_{g}\right)+\left(R_{g}-X_{g}-C_{g}\right) \\
\Delta_{4}=\kappa_{21}-\kappa_{22}=4 X_{g}+F
\end{gathered}
$$

Formula 9 greater than zero is always stands up, that is to say, even if the industry circle does not involve in industrial green transformation, the government is bound to promote industrial green transformation and carry out the energy conservation and emissions reduction policy. This shows that as the national management institution, it will undertake the main responsibility for energy conservation and emissions reduction. In order to increase social welfare, it can only rely on itself to promote industry green transformation.

Comprehensive analysis of the game model between government and industry circle above we can see that the key of government (industry circle) promotes (participates) industry green transformation is whether the revenue they obtain can greater than they cost. In addition, the government's external social benefits and the subsidies it spends are also the important factors that influence the government promoting industry green transformation, while when the industry circle is not willing to participate in the transformation, in order to enhance the level of social welfare and the performance of the social management, the government will also promote the industry green transformation. At the same time, economic benefits, government subsidies, government punishments and external social benefits are the key factors influencing the industry circle participating in industry green 
transformation. These are the interests demanding of the government and industry circle.

\subsection{Game Analysis between Industry Circle and Society}

Industry circle and society need to work closely in the industry green transformation (for example, society should give more support to the enterprises that implement the green transformation, buy green industrial products and services, etc.).In particular, the industry circle and society need to share the costs of industrial green transformation (for instance, industrial enterprises may add part of the environmental cost in the product price), and give more economic incentives to society, which can arouse the enthusiasm of social's participation. The following we will build a dynamic game model between the industry circle and society. First of all, the basic assumptions are as follows. (1) In the dynamic game model, there are two types of main body, industry circle $(R)$ and society $(M)$, respectively. Action sequence of the main body is the industry circle first acts, and the society observes the industry circle then decides to act. The game between the industry circle and society has complete information. (2) There are a lot of choices of action space of industry circle (such as environmental investment, technology research, human capital investment, etc.), in order to simplify the analysis, we use investment $S_{r}$ represents the behavior of the industry circle, society's action space is whether to participate in the industrial green transformation, which is $S_{m}$. Strategic space of the industry circle has a set of information, two optional actions, its strategic space is $S_{r}=$ \{investment, non- investment\}; Strategic space of the society has two sets of information, each information set has two optional actions, and its strategic space is $S_{m}=\{$ (participation, non-participation), (participation, non-participation), (non-participation, participation), (non-participation, non-participation) \}. (3) Assumes that the payoff function of industry circle is $W$, which denotes the investment behavior of industry circle in the industrial green transformation, $W=\left\{W_{l}, W_{2}\right\}=\{$ investment, non-investment $\}$; $K$ denotes the behavior of society participating in the industry green transformation, $K=\left\{K_{l}, K_{2}\right\}=$ \{participation, non-participation\}.Investment output (income) of industry circle is $P_{r}$, the investment cost is $C_{r}$, output and income are decided by joint participation of the industry circle and social, namely the $P_{r}=P_{r}\left\{W_{i}\right.$, $\left.K_{i}\right\}, C_{r}=C_{r}\left\{W_{i}, K_{i}\right\}, i=1,2$. The cost of society participating in the industrial green transformation is $C M i$, which is decided by its own strategic choice in the game. (4) The utility function of industry circle participating in industry green transformation is $U_{r}$, social utility function is $U_{m}$, which are both decided by joint participation strategies of the industry circle and social, namely, $U_{r}=U_{r}\left\{W_{i}, K_{i}\right\}, U_{m}=U_{m}\left\{W_{i}, K_{i}\right\}, i=1,2$. It is important to note that, only industry circle makes social net income of participation greater than non-participation in the game, social enthusiasm can be aroused, so it must meet the $C_{r}\left\{W_{l}, K_{l}\right\}-C M_{l} \geq C_{r}\left\{W_{l}, K_{2}\right\}-C M_{2}$.

As a result, the game between the industry circle and society is in line with the complete information dynamic game model, we show it in Figure 1.

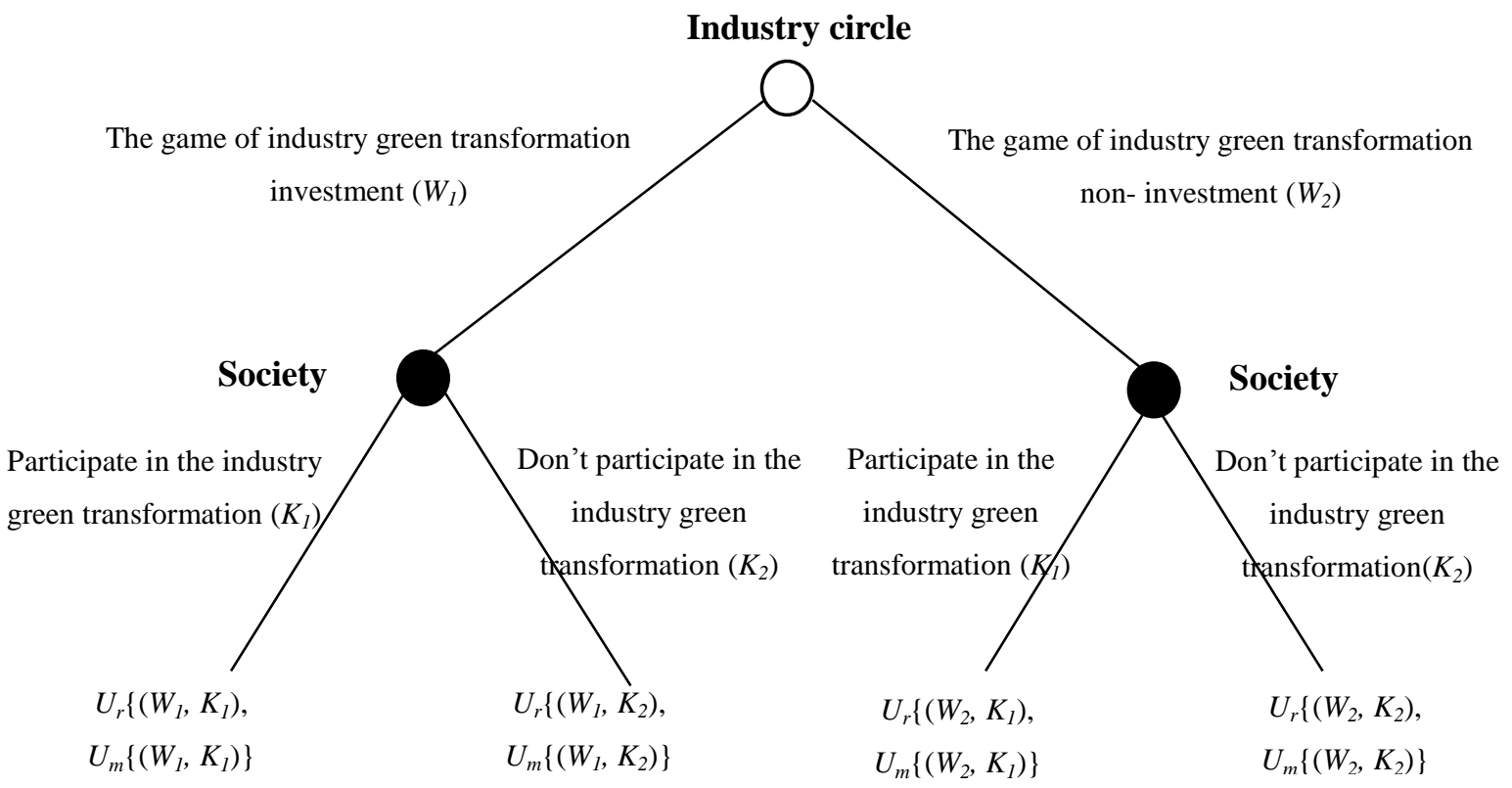

Figure 1 . The game between the industry circle and society

Based on the basic assumptions of the above game model, we use backward induction method to solve the 
"Sub-game Refined Bayesian Nash Equilibrium".

First of all, when $P_{r}\left(W_{1}, K_{1}\right)>C_{r}\left(W_{1}, K_{1}\right)$, the optimal choice of the society is $\tilde{K}^{*}$.

With regard to industry circle's investment $W_{1}$, the optimal solution is as formula10.

$$
\operatorname{MAX}\left\{U_{m}\right\}=\operatorname{MAX}\left\{U_{m}\left(W_{1}, K_{1}\right), U_{m}\left(W_{1}, K_{2}\right)\right\} \Rightarrow \quad \tilde{K}^{*}\left(W_{1}\right)=K_{1}
$$

With regard to industry circle's non-investment $W_{2}$, the optimal solution is as formula11.

$$
\operatorname{MAX}\left\{U_{m}\right\}=\operatorname{MAX}\left\{U_{m}\left(W_{2}, K_{1}\right), U_{m}\left(W_{2}, K_{2}\right)\right\} \Rightarrow \tilde{K}^{*}\left(W_{2}\right)=K_{2}
$$

The formula 10 and formula11 show that, when the industry circle invests, the optimal choice of society is to participate in the practice of transformation; when the industry circle does not carry on the investment of transformation, the optimal choice of society is not to participate in practice of transformation. It is fully show that the participation of social behavior is closely related to the behavior of the industry circle, if the industry circle does not carry on transformation investment and take related transformation costs, the society will not follow the steps to carry out the implementation of the green transformation. If the industry circle invest more and can make social benefit in this action, the enthusiasm of social participation will be improved.

For industry circle, the optimal choice is as formula 12.

$$
\operatorname{MAX}\left\{U_{r}\right\}=\operatorname{MAX}\left\{U_{r}\left(W_{1}, K_{1}\right), U_{r}\left(W_{2}, K_{2}\right)\right\} \Rightarrow W^{*}=W_{1}
$$

Thus, we can get "Refined Bayesian Nash Equilibrium" is \{investment, (participation, non-participation) \}. Namely under the condition of the output is greater than the cost, the optimal choice of industry circle is to take investment behavior in the game, while for the society, it may choose to participate in or may choose not to participate in, the key of participation lies in whether the industry circle will take the action first and make social net income greater than the cost.

Secondly, when $P_{r}\left(W_{1}, K_{1}\right) \leq C_{r}\left(W_{1}, K_{1}\right)$, the optimal choice of the society is $\tilde{\tilde{K}}^{*}$.

With regard to industry circle's investment $W_{1}$, the optimal solution is as formula 13 .

$$
\operatorname{MAX}\left\{U_{m}\right\}=\operatorname{MAX}\left\{U_{m}\left(W_{1}, K_{1}\right), U_{m}\left(W_{1}, K_{2}\right)\right\} \Rightarrow \tilde{\tilde{K}}^{*}\left(W_{1}\right)=K_{1}
$$

With regard to industry circle's non-investment $W_{2}$, the optimal solution is as formula14.

$$
\operatorname{MAX}\left\{U_{m}\right\}=\operatorname{MAX}\left\{U_{m}\left(W_{2}, K_{1}\right), U_{m}\left(W_{2}, K_{2}\right)\right\} \Rightarrow \tilde{\tilde{K}}^{*}\left(W_{2}\right)=K_{2}
$$

For industry circle, the optimal choice is as formula15.

$$
\operatorname{MAX}\left\{U_{r}\right\}=\operatorname{MAX}\left\{U_{r}\left(W_{1}, K_{1}\right), U_{r}\left(W_{2}, K_{2}\right)\right\} \Rightarrow W^{*}=W_{2}
$$

Comprehensive analysis of formula 13, 14, 15, we can get "Refined Bayesian Nash Equilibrium" is $\{$ non-investment, (participation, non- participation)\}.This means that when the invest revenue of industry circle outweigh the cost, as long as it willing to invest, the society will choose the strategy of participation, and if it is reluctant to invest, the strategy of society is non-participation. The invest behavior of industry circle not only relate to its own interests, but also have an important impact on social participation. However, if the industry circle does not arouse the enthusiasm of society, making little revenue, the optimal selection strategy of industry circle is non-investment.

Through the above analysis, we can get the following conclusions: firstly, the key of whether the industry circle chooses investment is making its own revenue outweigh the cost in the game. If the effect of investment strategy is obvious, no matter how society chooses, it willing to invest in industry green transformation. Secondly, if the investment output less than the cost by industry circle, namely the implementation plan of industry circle cannot arouse the enthusiasm of social participation, so as to make the reform develop slowly and get little effectiveness, the industry circle will lose its motive to invest. Thirdly, when industry circle implements investment strategy, the society may not participate in accordance with the industrial willingness, at this time, it requires the government come and take compulsory means, clear industry, society and other related bodies' responsibilities, 
and give powerful economic incentives, and strengthen inspection and supervision, so as to boost the transformation smoothly and achieve the maximization interests of the whole society.

\section{Practical Mechanism of China's Industry Green Transformation}

Through all-round game model of different interest bodies, we can see that, it is not easy to achieve cooperation among all bodies during the process of transformation. Due to the interest demands of main bodies in the game is different, if the interests cannot be balanced and the demands cannot be satisfied effectively, it can't give full play of all bodies' strength. Among key bodies, such as the government, industry circle, industrial enterprises, society and the public, if any part cannot participate in the reform and cooperation, it cannot guarantee the smooth development of industry green transformation. Therefore, on the basis of summarizing the game model, we will start from the interest demands of the bodies, combine with the actual situation of china's industrial green transformation, and design the practical mechanism, further to lay a foundation for constructing the strategic and political framework of industry green transformation.

The practical mechanism of china's industry green transformation needs a comprehensive, systematic and open strategic framework and the extensive participation of the government, industry circle, industrial enterprises and social public. During such a progress, all participants have their own responsibility and function. Meanwhile, they have their own interest demands. All bodies cooperate, coordinate and influence each other, jointly promote the practice of industry green transformation.

\subsection{Leading Body: Government}

During the practice of china's industry green transformation, the government has played the leading role. Of which, the central government is the top leader, in charge of developing national strategies and policies. Local government is under the leading of central government, in charge of developing and implementing the specific strategies conforming to the local realities. In reality, from the central to local government, in order to greatly promote the industry green transformation, the government has published all kinds of laws, plans and policies, with the hope of forming a cornerstone of the industry green transformation. For instance, the national "Eleventh Five-year Plan", "Twelfth Five-year Plan" and even the early plan of "Thirteenth Five-year" have put forward to speed up the industrial transformation and green development. Through these policies, regulations and management ordinance, the government hopes that, on one hand, they can strengthen the management and restraint on the industry, and also specify the standard and regulations of industrial green transformation. On another hand, they can improve the reward and punishment mechanism for industrial green transformation, so as to let the industrial circle realize the expected target under the dual effect of stimulus and restraint. However, the executing effect of governmental policies is not so ideal. The discrepancy between the policy-setting and industrial development contributes to this effect. In addition, for the purpose of political performance, the local government loosens related environmental management rule, which results in discrepancy of political executing. In the game model, we can see that, if the government has slight political executing or investment effect, which will seriously frustrate the enthusiasm of the government. Therefore, the practical mechanism of industrial green transformation is beneficial for all bodies to make positive cooperation and form close cooperation led by the government, further to form green cohesive force for green development.

Meanwhile, through the game models, we can see that, the government needs a lot of human power, material resources and financial resources to promote the industry green transformation. However, if the government makes too much investment with low revenue, it will frustrate the enthusiasm of government. So, it is needs that all bodies can share part of cost under the situation of taking the government as the main force. Currently, the industrial green transformation has still been developed by relying on the financial funds of government. The mechanism of collecting funds through the industrial circle, social public and financial institutions has not been established. Therefore, the entire society needs to widely participate in the practice of industrial green transformation, establish multi-channel financing mechanism and share the reforming cost of government. The game model also shows that, the support from own society and international society for the government is crucial. Chinese government has always placed the energy saving and emission reduction at the height of national strategy. As the main force of energy saving and emission reduction, the industry naturally occupies an important position. To promote the industry green transformation, the government aims at saving the energies, protecting the ecological environment, maintaining the sustainable development of economy and playing the role of a big responsible country in the international society. The own society needs to offer great support and respond to the call of the government. The international society also needs to affirm China's reform.

\subsection{Executing Body: The Industry Circle, Industrial Enterprises and Social Public}

To smoothly implement the industry green transformation, the industry circle and industrial enterprises are the 
most important bodies. Responding of the industry circle includes two aspects: making detailed rules and regulations on developing industrial green transformation and industrial transformation. To every industry, its task and objective of green transformation varies from each other, and their responding sensitivity to the governmental policies is different from each other. Based on the policies of government, it urgently needs the industry circle develop differentiated industrial standard and enforcement regulations, which targeted at the characteristics and development status of different industries. Industrial transformation includes two aspects: reforming and upgrading of traditional industry, and developing green industry. Only if the industry circle promotes the industrial transformation and upgrading and expansion of green industry as a whole, can it stimulate every industrial enterprise to speed up the autonomous activity. Therefore, it is the important responsibility for the industry circle to speed up the adjustment of industrial structure, devote greater efforts to the emerging industries, further to construct the green industrial system. For industrial enterprises, the practical mechanism mainly includes technological R\&D, talent cultivation and green product. The industrial enterprises are the core microcosmic bodies to promote industrial green transformation. Green technological R\&D is the essential guarantee for green transformation of enterprises. Only by gradually improving the green technological system, can the enterprises stimulate the enthusiasm for innovation and possess sustainable competitiveness. During such a process, talent cultivation is the core support for technological R\&D and innovation. Green product means to realize the greening of industrial enterprises' terminal products. As a consequence, industrial enterprises need to offer more green products and services by promoting the product ecological design, promoting technological innovation and commercial mode innovation. According to the game model talked above, the industry circle (industry and enterprises) is the main force for the industrial green transformation practice. In order to give full play to the role of main force, it needs to satisfy the essential requirement of the industrial circle, namely the pursuit of economic benefits. If the industry circle cannot obtain good economic benefits after participating in the transformation practice or the cost surpasses the benefits, the enthusiasm of industry circle cannot be stimulated. From the reality, to promote the green transformation, the industry circle needs to cost a lot. No matter the transformation and upgrading of traditional industry or the investments in the emerging green industries, enterprises need to bear heavy cost burden. Therefore, in the beginning stage of promoting green transformation, the government needs to offer certain subsidies or tax preferences for the industrial circle, so as to help enterprises obtain good economic profits. Meanwhile, in practice, the industry circle needs to spend a lot on the technological R\&D. One single enterprise cannot take out enough funds to complete this systematic project. Therefore, it urgently needs the government to give full support, not only the policy, but also the funds.

To realize the industry green transformation, the social public mainly achieves that through support of public opinion and purchasing power. The social public's attention and support for the industry green transformation is an important link for promoting enterprises to participate in transformation. The game model shows that, recognition from the external society is the incentive for enterprises to take part in transformation. Sound external benefits of the society can stimulate industrial enterprises to better take part in the reform, strengthen the technological R\&D and innovation, and also give full play of the enterprises as the main force. Under the background of national energy conservation and emission reduction, the whole society should form a good atmosphere of public opinion, fully considerate and support the transformation and development of industrial enterprises, and then establish good public praise and image of industrial enterprises through propaganda and encouragement of good examples. On another hand, the social public's support for the industrial green transformation is still embodied in the purchase of green products and services. The value of enterprises is essentially realized by selling products and services. The society has much stronger purchasing power of green industrial products, it can better promote the industrial enterprises to change the development idea and stimulate the industrial circle's practice in deepening green transformation.

\subsection{Supporting Body: Financial Institution, Transaction Center, Scientific Research Institution, Industrial Associations and International Center, etc.}

Except for the above important bodies, the implementation of industry green transformation is still supported by a series of supportive bodies. Although they are not the direct participants of the industry green transformation, they have important supporting meanings for guaranteeing the transformation practice. Led by the government, the financial institutions offer green financial support for the industrial green transformation. The government can set up all kinds of scientific and financial cooperative platform, guide financial institutions to take part in development of green technology and encourage financial institutions to strengthen the financial services for enterprises with green technology. Meanwhile, except the financial institutions as banks, it should improve the financial market's service system of china, and promote diversified financing method of green industry. The 
government can lead insurance companies, security companies, fund management corporations and leasing companies to offer diversified financing channels for the green development of enterprises. Transaction centers mainly refer to the market-oriented plates targeted at transactions of industrial pollution's emission rights. As the economic system based on the market, the pollution's emission right has economic stimulus for the industrial enterprises, which lies in that, the selling party of the emission right has the surplus right due to excessive emission reduction and it obtains economic rewards by selling the left emission right. As a matter of fact, it is the market's compensation for the environmental-protection behavior of industrial enterprises. For instance, the carbon emissions permit trading center is a typical case. Scientific research institutions can offer important technical support and talent support for the industry green transformation. The industrial circle, scientific research institutions and universities need to construct a cooperative network with extensive technology and talents, develop fill cooperation in the aspect of theoretical innovation, scientific R\&D, information network and resource sharing etc., so as to guarantee that industrial enterprises can have enough R\&D impetus and innovative enthusiasm. Besides, scientific research institutions will provide green talents for the industrial circle, who will cover all fields of the green industry, such as "new energy", "new material", "new equipment", etc. They are the intelligent foundation for the sustainable development of industrial economy. The industrial associations represent the overall benefits of the industrial circle, which can formulate unified system and standard for the industry, fully arouse the industrial enterprises' enthusiasm through system innovation and effective management. The industrial associations still play the role of spokesman of the industrial enterprises, it will reflect their problems and bottlenecks during the process of green transformation, and also maintain legal profits of the industrial enterprises. The establishment of international center mainly aims at promoting global treatment and international coordination of promoting energy, environment, coping with climate change, further to create good external environment.

\section{Strategic Choice of China's Industry Green Transformation}

\subsection{Strategy of Central Government}

For the central government, first of all, it should take full advantages of the opportunity of global green new deal, speed up to formulate corresponding policies, further to promote industry green transformation. By taking green transformation as Chinese industrial guiding philosophy of "transforming from big to strong", it should make an unified plan and determine the strategic goals, fields for preferential development, strategic layout and major tasks of industry green transformation. Under the guidance of unified strategic plan, it should coordinate the responsibilities and obligations of all regions and industries for green transformation, fully display all regions' willing and conditional differences for transformation, further to provide basis for regions and industries to publish supporting policies and guarantee measures for industrial green transformation. Secondly, the central government needs to reform the current performance evaluation system, which is inclined to take GDP as the core, explore and establish one set of political performance evaluation system suitable for promoting green economy. Moreover, it needs to strengthen the industrial enterprises' and normal residents' understanding about developing green economy and recycled economy through policies and social influential power of laws. During the reforming process, it especially needs to incorporate the resource, environment and related elements into the evaluation scope. As the related restraint elements such as industrial energy conservation and emission reduction should occupy an important position in the government's evaluation and punishment system. Because the social public's support plays a crucial role in industry green transformation, it can introduce the public's satisfaction into the evaluation process, thus the public's environmental willing can have impact on the career of governmental officials. Thirdly, it should implement the green taxation system. By fully taking advantage of taxation level, it can extend the preferences for product R\&D and application. In the aspect of value-added tax, it has to carry out certain preferential policy as VAT deduction for the significant energy conservation equipment and products which have extremely obvious effects on energy conservation while promotion is not smooth because of the price restriction. Fourthly, it should strengthen the central financial support for industrial green transformation, further set up and improve the financial credit system, marketing system, scientific talent system, and international cooperative system to support industry green development. Construct multi-formed and diversified green industrial cooperative platform, so as to fully guarantee the industry green transformation.

\subsection{Strategy of Region}

Local government should publish a series of operable and predictable rules for the implementation, which based on national policies and regulations, targeted at the green industrial development and combined with the real situation of regional industrial development. First of all, according to china's restraint requirement on the industrial energy conservation and emission reduction, it can perfect the local environmental system. It should improve the intensity of the government's environmental regulation, and stimulate enterprises to realize 
innovations in pollution treatment technology and production technology. In addition, targeted at the actual situations of local industrial development, it can develop differentiated, reasonable and dynamic environmental regulations. Meanwhile, the government needs to establish effective motivating measures for environmental regulations. In the future, it should apply more market-oriented regulatory tools, such as pollution discharge fee (tax), pollutant discharge permit, etc. Secondly, it should strengthen the local government's investment in R\&D of green industry technology, and also pay attention to the improvement of attracting investment. It should reinforce the independent R\&D ability and perfect the technical standards and management practices of green manufacturing, guide and encourage the governmental and private capital to jointly enter the R\&D field of green industry. When undertaking industrial transferring projects from other countries and regions, it cannot blindly pay attention to the quantity, but carefully select clean and environmental protection enterprises which have low energy consumption, advanced technology and management experience, so as to promote the green layout of industrial development. Thirdly, it should improve the governmental green purchasing system. The government should publish policies for purchasing green products with financial support. Local government at all levels can set up a green purchasing network for the convenience of communicating. Fourthly, it should strengthen regional collaboration and improve the benefit compensation mechanism. Regions with close economic relations can establish an industrial pollution control leading team for joint prevention and controlling, adopt a regionally unified industrial pollution prevention regulation, industrial access standard and pollution monitoring network. By adopting the way of joint law enforcement of all provinces and cities, it can reinforce the effectiveness of punishing illegal pollution behavior within the region.

\subsection{Strategy of Industry}

The industry circle is the collection of many industrial sectors and enterprises. Green transformation at industrial level has important guidance and orientation for the green development of micro-enterprises. Strategies at industrial level mainly include the following aspects: first of all, it should accelerate the promotion of green economy, vigorously develop the industrial clustering. On one hand, it should establish the ecological industrial park. Mainly relying on ecologization, integration, intellectualization and informatization, the ecological industrial park should develop the ecological plan and pollution control. On the other hand, the green industrial park is set up in hi-tech development zone. Recycled industry is the effective subject of green economy. The selected demonstration enterprises should conform to the concept of recycled economy, carry out energy conservation and emission reduction by product ecological design, recycled utilization and clean production, establish industrial symbiotic and metabolic ecological chain, and then construct the micro-foundation of recycled economy. Secondly, it should accelerate the industrial structural adjustment and construct green industrial system. On one hand, it should reform traditional industry, close down outdated production facilities, improve the greening level of traditional industry by advanced technology and standard, so as to try to transform from "end-of-pipe control" to "cleaner production". On the other hand, it should increase the green investments, devote great efforts to developing emerging industries and new energy industries, further to positively promote the industrial transformation and upgrading. Thirdly, it should promote industrial integration. Currently, it is the most important thing to develop R\&D service industry and information industry, increase the efficiency of the manufacturing industry at all stages, improve the output value, further to promote industry green transformation. On one hand, it should guide to establish $\mathrm{R} \& \mathrm{D}$ alliance, promote the integrated industry-university-research cooperation, develop R\&D outsourcing etc. On the other hand, it should devote great efforts to developing software service, information value-added service and network service. It should focus on promoting mobile communication, digital TV, internet, etc. Fourthly, it should optimize the industrial export trade structure. It should promote the coordination between domestic and external demand, encourage industry to speed up the transformation and upgrading, increase the development and utilization of resources abroad and energies, devote great efforts to introducing advanced green technology and key equipment, further to optimize and improve the structure of industrial trade.

\subsection{Strategy of Enterprise}

Industrial enterprise is the direct executing body promoting industry green transformation, whose green transformation is successful or not directly related to the general situation of national industry green development. Strategic choices at enterprise's level mainly include the following aspects: first of all, it should positively implement the green technology $R \& D$ and gradually form the green technological system. For instance, it should effectively give play of the advanced technology in energy conservation and emission reduction, optimize the deep processing technology of fossil fuels, such as kerosene, promote cleaner production and cyclic utilization, increase the added value and usage effectiveness of energy, guarantee the safe supply of energy and control the emission of greenhouse gases. Secondly, it should increase the informatization level of 
industrial enterprises. By applying the information technology, it can implement ERP, SCM, CRM, FMS and CIMS, so as to realize the integration of production, management and control, and the unify of production and marketing, management and service, further to let the traditional industrial enterprises abide by the principle of green economy, produce products with low consumption, less pollution and high additional value. Thirdly, the industrial enterprises should reinforce the construction of talent cultivation system and offer talents guarantee for industry green transformation. By strengthening the cooperation with scientific institutions, universities and colleges, industrial incubator base etc., it can construct open and innovative cooperative network of green industry, so as to realize the sharing of technological resources, information resources and base resources. During such a process, it should devote great efforts to introducing talents from the fields of new energy, new materials and high-end equipment, set up professional, comprehensive and solid talent pool with proper gradient. Fourthly, it should strengthen the ability of digestive absorption and re-innovation after introducing green technology, encourage local powerful industrial enterprises to play the role of "agent for introducing green technology", fully participate in the global value chain, make close cooperation with advanced enterprises of developed countries, further to promote the improvement of the whole industrial green technology innovative ability. Therefore, it should reinforce the enterprises' ability of digest, absorb and re-innovate, form the intellectual property rights of green industry, further to improve the ability and level of industrial green self-dependent innovation.

\subsection{Strategy of Society and Individual}

Industry green transformation cannot neglect the strength of social or individual participation. Strategic selections at social and individual level mainly include the following aspects: first of all, the news media should give full play to its role in environmental protection, positively publicize all kinds of laws and regulations beneficial for industrial green transformation, further to create good social atmosphere for green innovation and development. The society can also give the play of supervision by public opinions, which should expose and criticize industrial enterprises that polluting the environment. The society should also positively publicize and expose the performances and deficiencies of regional industrial green transformation, so as to form a multidirectional feedback mechanism that the public supervises the function fulfillment of government and enterprise. Secondly, it should guide the public to spontaneously take part in the activity of treating industrial pollution, and form the social cultural recognition system of "green industry, green city". Industrial pollution control should not only rely on the reform or upgrading of "hard environment", but also attach more importance to the upgrading of informal institution "soft environment". Establishment of public recognition can be done from themselves, further to cultivate correct and environmental-friendly life consumption mode. The citizens should spontaneously resist behaviors of environmental pollution, and implement energy conservation and emission reduction in production and life. Thirdly, encourage the society and individuals to use energy-saving and environmental-friendly industrial products and services, so as to support industrial green transformation from the perspective of purchasing power. The social public should positively use industrial products with the green labels, and the green products are the final embodiment of enterprises' green technology application that will directly promote the people to transform their consumption concept and production method. If purchasing of green products to be a fashion, the enterprises will be more inclined to produce green products. For enterprises, green label is the green ID for product, which is the main guarantee for enterprises to obtain governmental support, trust of consumers and development of green marketing.

\section{References}

Angang, H. (2012). Green GDP, Low-Carbon Development. People’s Tribune, (1), 25-25.

Bei, J. (2011). Transformation and Upgrading of Chinese Industry. China Industrial Economics, (7), 5-14.

Guoshen, Z. (2009). Researches on Ecological Industrial Development. Fujian Normal University, Fuzhou.

Hongming, L. (2009). Ecological Civilization-Oriented China's Industrial Green Development Strategy. Ecological Economy, (1), 321-324.

Junan, L. (2014). China's Industry Green Development Based on Innovation Driving. Reform and Strategy, (1), 97-100.

Qingxin, L., \& Jing, H. (2012). Strategic Research of China's Industrial Green Transformation. Reform of the Economic System, (1), 24-28.

Research Group of Institute of Industrial Economics of Chinese Academy of Social Sciences. (2011). Researches on China's Industrial Green Transformation. China Industrial Economics, (4), 5-14.

Weimin, J., \& Lu, Z. (2014). Environmental Regulations, Opening Up and China's Industrial Green Technology 
Progress. Economic Research, (9), 34-47.

Yan, C. (2013). Industrial Green Low-carbon Energy Conservation Development Strategy-Research on Strategic Selection of Basic Industrialization in China. Review of Economic Research, (68), 41-43.

Yihu, W., \& Wen, C. (2007). Motivation Mechanism of Industrial Green Development. Journal of Central China Normal University, (3), 125-129.

\section{Copyrights}

Copyright for this article is retained by the author(s), with first publication rights granted to the journal.

This is an open-access article distributed under the terms and conditions of the Creative Commons Attribution license (http://creativecommons.org/licenses/by/3.0/). 